\title{
Underwater endoscopic mucosal resection of residual duodenal tumor
}

A 51-year-old man underwent screening esophagogastroduodenoscopy (EGD) and was found to have a $15-\mathrm{mm}$ duodenal adenoma opposite the ampulla of Vater. Endoscopic submucosal dissection (ESD) was attempted but was discontinued because of a perforation that was managed by clip closure. He was followed up periodically by EGD and a biopsy taken 2 years later revealed a possible adenocarcinoma. He was therefore referred to our hospital.

EGD revealed a superficial 20-mm elevated lesion ( $\triangleright$ Fig. 1 a). Conventional endoscopic mucosal resection (EMR) of the residual tumor with submucosal saline injection would have been difficult because of submucosal fibrosis. Furthermore, ESD for duodenal tumors carries a high risk of perforation [1], and performing ESD on residual lesions demands highly advanced skills. Underwater EMR (UEMR) was developed and described by Binmoeller et al. in 2012 [2]. We previously reported the usefulness of this technique for superficial non-ampullary duodenal adenomas [3]. As for colonic recurrent or residual lesions, UEMR is reportedly effective with a higher en bloc resection rate and lower recurrence rate than conventional EMR [4]. We therefore performed UEMR on this residual duodenal lesion.

We used a pediatric colonoscope (EVIS PCF-H290TI; Olympus Medical Systems, Tokyo, Japan) because it is preferable for duodenal lesions owing to its long length and wide down-angle. We evacuated air from the affected segment of lumen and infused water until the lumen was

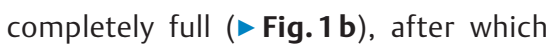
we performed hot snare polypectomy without submucosal injection using a Captivator (Boston Scientific, Tokyo, Japan). We resected the lesion en bloc in 4 minutes and completely closed the mucosal defect with clips ( $\triangleright$ Fig. 1 c, d; - Video 1).


- Fig. 1 Endoscopic images showing: a a tumor in the duodenum opposite the ampulla of Vater; $\mathbf{b}$ the polyp underwater; $\boldsymbol{c}$ the mucosal defect after underwater endoscopic mucosal resection had been performed, with a vessel visible in the defect; $\mathbf{d}$ complete closure of the defect using clips.

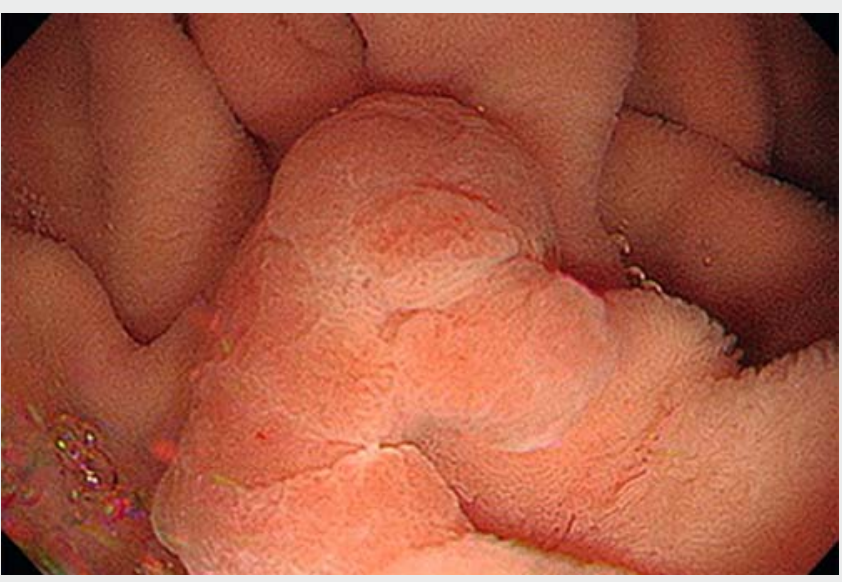

Video 1 Underwater endoscopic mucosal resection of residual duodenal tumor. 


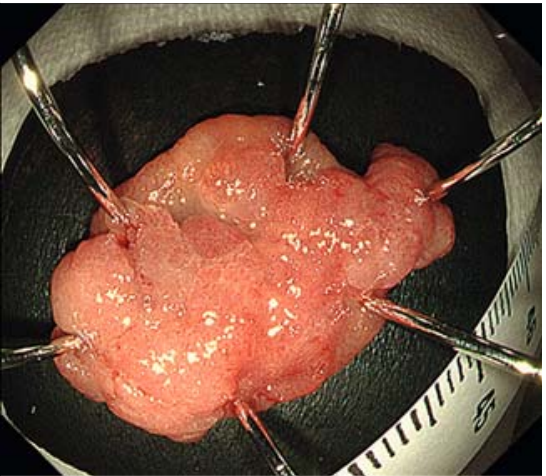

- Fig. 2 Photograph of the resected en bloc specimen.

The patient commenced oral feeding on day 2 postoperatively and was discharged on day 5. Pathologically, the lesion was an intramucosal adenocarcinoma (> Fig. 2). Neither endoscopic nor histologic residue was observed at the follow-up EGD 2 months later.

Endoscopy_UCTN_Code_TTT_1AQ_2AD

Competing interests

None
The authors

Satoki Shichijo, Noriya Uedo, Yoji Takeuchi, Hiroyoshi Iwagami, Masayasu Ohmori, Shuntaro Inoue, Ryu Ishihara

Department of Gastrointestinal Oncology, Osaka International Cancer Institute, Osaka, Japan

Corresponding author

\section{Satoki Shichijo, MD, PhD}

Department of Gastrointestinal Oncology, Osaka International Cancer Institute, 3-1-69 Otemae, Cyuo-ku, Osaka 541-8567, Japan Fax: +81-6-69814067

shichijiyou-tky@umin.ac.jp

\section{References}

[1] Yahagi N, Kato M, Ochiai Y et al. Outcomes of endoscopic resection for superficial duodenal epithelial neoplasia. Gastrointest Endosc 2018; 88: 676-682

[2] Binmoeller KF, Weilert F, Shah J et al. "Underwater" EMR without submucosal injection for large sessile colorectal polyps (with video). Gastrointest Endosc 2012; 75 : 1086-1091
[3] Yamasaki Y, Uedo N, Takeuchi Y et al. Underwater endoscopic mucosal resection for superficial nonampullary duodenal adenomas. Endoscopy 2018; 50: 154-158

[4] Kim HG, Thosani N, Banerjee S et al. Underwater endoscopic mucosal resection for recurrences after previous piecemeal resection of colorectal polyps (with video). Gastrointest Endosc 2014; 80: 1094 - 1102

\section{Bibliography}

DOI https://doi.org/10.1055/a-0919-4357

Published online: 4.6.2019

Endoscopy 2019; 51: E329-E330

(c) Georg Thieme Verlag KG

Stuttgart · New York

ISSN 0013-726X

\section{ENDOSCOPY E-VIDEOS \\ https://eref.thieme.de/e-videos}

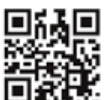

Endoscopy E-Videos is a free access online section, reporting on interesting cases and new

techniques in gastroenterological endoscopy. All papers include a high quality video and all contributions are freely accessible online.

This section has its own submission website at https://mc.manuscriptcentral.com/e-videos 